\title{
Protective roles of Pyracantha fortuneana extract on acute renal toxicity induced by cadmium chloride in rats ${ }^{1}$
}

\author{
Yixin Ke' (D) , Kaihang Yu" (D) , Weiliang Zeng ${ }^{\prime \prime \prime}$ (D) , Guojun Lian ${ }^{\prime V}$ (iD
}

' Graduate student, Department of Health Inspection and Quarantine, School of Laboratory Medicine and Life Science, Wenzhou Medical University, Wenzhou, China. Conception and design of the study, acquisition of data, technical procedures, manuscript preparation and writing.

"Graduate student, Department of Health Inspection and Quarantine, School of Laboratory Medicine and Life Science, Wenzhou Medical University, Wenzhou, China. Technical procedures, acquisition of data.

"'Graduate student, Department of Health Inspection and Quarantine, School of Laboratory Medicine and Life Science, Wenzhou Medical University, Wenzhou, China. Statistical analysis, interpretation of data.

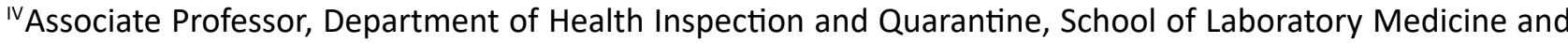
Life Science, Wenzhou Medical University, Wenzhou, China. Conception and design of the study, acquisition of data, technical procedures, manuscript preparation and writing, final approval.

\begin{abstract}
Purpose: To investigate the protective roles of pyracantha fortune fruit extract (PFE) on acute renal toxicity induced by cadmium chloride $\left(\mathrm{CdCl}_{2}\right)$ in rats.

Methods: Rats were pretreated with PFE and consecutively injected with $\mathrm{CdCl}_{2}(6.5 \mathrm{mg} / \mathrm{kg})$ for 5 days.

Results: The concentration of $\mathrm{Cd}$, kidney weight, malondialdehyde (MDA), and nitric oxide (NO) production were remarkably increased in $\mathrm{CdCl}_{2}$ group as well as the levels of plasma uric acid, urea, and creatinine $(P<0.001)$. However, the body weight and glutathione $(G S H)$, superoxide dismutase $(\mathrm{SOD})$, catalase (CAT), glutathione peroxidase (GPX) and glutathione peroxidase (GR) levels were markedly reduced by $\mathrm{CdCl}_{2}$ treatment $(P<0.001)$. Histological manifestations of renal tissue showed severely adverse changes. Moreover, $\mathrm{CdCl}_{2}$ treatment significantly decreased the $\mathrm{B}$-cell lymphoma-2 $(\mathrm{Bcl}-2)$ expression while increased the $\mathrm{BCl}-2$-Associated $X$ Protein (Bax), tumor necrosis factor- $\alpha$ (TNF- $\alpha$ ) expression $(P<0.001)$. Additionally, the expression of Nrf2/Keap 1 related proteins Keap-1 gained a significant increase $(P<0.001)$, whereas the Nrf2, HO-1, $\gamma-\mathrm{GCS}, \mathrm{GSH}-\mathrm{Px}$ and NQO1 expression decreased by $\mathrm{CdCl}_{2}$ treatment $(P<0.05)$. These rats were pretreated with PFE to improve the changes caused by $\mathrm{CdCl}_{2}$ treatment.
\end{abstract}

Conclusion: PFE could protect the kidney against acute renal toxicity induced by $\mathrm{CdCl}_{2}$.

Key words: Pyracantha. Acute Toxicity. Cadmium Chloride. Apoptosis. Kidney. Rats. 


\section{- Introduction}

Cadmium ( $\mathrm{Cd}$ ) is designated as an endocrine disruptor/endocrine disrupting chemical (EDC), a potential toxicant metal derived from horticultural and industrial sources ${ }^{1}$. It is a pollutant for most human foods because it has a high soil-plant transmission rate, making diet a main source of contact ${ }^{2}$. The level of $\mathrm{Cd}$ toxic in kidney, lung and testis tissues has been determined $^{3}$. A previous study reported that many transporters play important roles in the accumulation of $\mathrm{Cd}$ in kidney tissue, including metallothionein, $\mathrm{Cd}$ binding proteins containing thiol (-SH) groups and divalent metal ion transporter $1^{4}$. $\mathrm{Cd}$ accumulates in kidney to produce reactive oxygen species (ROS), which leads to inflammation, oxidative stress, glomerular dysfunction and programmed cell death ${ }^{5}$, and interferes with basic elements such as calcium and zinc ${ }^{6}$. The S1 and S2 segments of the proximal convoluted tubule are the target sites of renal tissue toxicant, leading to renal dysfunction ${ }^{7}$. In addition, $\mathrm{Cd}$ is considered as the cause of lipid peroxidation and is generally considered to be the major cause of the deleterious effects on membrane-dependent function ${ }^{8}$, which makes the kidney more vulnerable to cadmium. Due to the lack of adequate methods for treating cadmium nephrotoxicity, there is an increasing interest in the use of antioxidants to prevent the kidney from the toxicity of $\mathrm{Cd}$.

Pyracanthafortuneana (Pfortuneana), one of Maloideae subfamily, mainly distributed in the southwest of China ${ }^{9}$ rich in polyphenols such as rutin, and its hexose compound, and polymeric (epicate)-catechin (proanthocyanidin 2, $\mathrm{PB} 2)^{10}$. In previous studies, the optimal $P$. fortuneana fruit extract (PFE) is obtained via chemical antioxidant activityguided extraction ${ }^{11-13}$. Previous reports showed that $P$. fortuneana extracts inhibit the inflammatory reactions in mice, reduce oxidative stress, and reduce liver damage in mice by carbon tetrachloride $(\mathrm{CCl} 4)^{12,14}$. However, it remains unclear whether PFE plays a role in cadmiuminduced nephrotoxicity.

Keap1/Nrf2 is an important regulatory pathway in the process of oxidative stress. Keap1 is a blocker protein in the Kelch family, which usually presents on the cytoplasmic actin cytoskeleton and is a negative regulatory protein of Nrf2 ${ }^{15}$. Nrf2 belongs to the Cap-n-Collar (CNC) regulatory protein family and is a key transcription factor in cellular antioxidant stress. It is inactive with Keap1 in the cytoplasm under physiological conditions. When the body is stimulated by other nucleophiles or in an oxidative stress state, Nrf2 is dissociated from Keap1, and after Nrf2 phosphorylation, it is transferred into the nucleus and binds to the antioxidant response element (ARE), which initiates ARE-regulated downstream phase
II metabolic enzymes and antibiotics. The expression of the oxidized protein gene enhances the body's ability to resist oxidative stress ${ }^{16}$. This study aims to investigate the potential protective effects of PFE administration on acute nephrotoxicity in a rat model of cadmium exposure. The antioxidant and anti-apoptosis activities of PFE make it to achieve these antioxidant protection effects via Nrf2/Keap 1 pathway. Therefore, the use of PFE may be beneficial for renal toxicity caused by $\mathrm{CdCl}_{2}$.

\section{- Methods}

\section{Chemicals}

$\mathrm{CdCl}_{2}$ and other chemicals for histological, biochemical analysis were obtained from Sigma (St Louis, MO, USA).

\section{Pyracantha fortune fruit}

The pyracantha fortune fruit was collected from the Mount of Wuling (Hubei Province, China) in August 2018. A specimen is deposited in the Institute of Traditional Chinese Medicine and Natural Products, Guangzhou University of Traditional Chinese Medicine (Guangzhou, China). The pyracantha fortune fruit (air-dried, $10.0 \mathrm{~kg}$ ) was refluxed twice with $25 \mathrm{~L} 60 \%$ ( $\mathrm{v} / \mathrm{v}$, aqueous/ethanol) for 2 hours repeatedly. Then, leachate got dried under vacuum conditions and the remnants got dissolved in distilled water and stored in a closed bottle under the temperature of $-20^{\circ} \mathrm{C}$. The extracts were specified as pyracantha fortuneana extract (PFE) ${ }^{17}$.

\section{Animals}

Thirty-two-adult male Wistar rats (7-8-week-old, weighing 150-170 g) were purchased from Guangdong Medical Lab Animal Center (Foshan, China). The rats were placed at the Animal Experimental Center of Guangzhou University of Traditional Chinese Medicine at room temperature with 12 -h light/dark cycles. Rats were able to obtain granular rodent feed and water and were randomly divided into control group [intraperitoneally (i.p.) injected, $0.9 \% \mathrm{NaCl}$ (physiological saline) daily for 5 days], $\mathrm{CdCl}_{2}$ group (injected i.p., $6.5 \mathrm{mg} / \mathrm{kg} \mathrm{CdCl}_{2}$ daily for 5 days), PFE group (orally administered, $250 \mathrm{mg} /$ $\mathrm{kg}$ ) and PFE $+\mathrm{CdCl}_{2}$ group (pretreatment administered $250 \mathrm{mg} / \mathrm{kg}$ PFE $1 \mathrm{~h}$ before injecting $6.5 \mathrm{mg} / \mathrm{kg} \mathrm{CdCl}$ i.p. daily for 5 days) ( $n=8$ in each group) ${ }^{18}$. Rats were euthanized after a final dose for 24 hours (beheading). A $10 \%(\mathrm{w} / \mathrm{v})$ homogenate was prepared for analysis. Briefly the kidneys of rats were dissected, weighed, and immediately homogenized in $10 \mathrm{mM}$ phosphate buffer ( $\mathrm{pH}$ 7.4) with ice-cold. All animal experiments 
were accordant with the Committee on Research Ethics for Laboratory Animal Care at the Animal Experimental Center of Guangzhou University of Traditional Chinese Medicine, and approved by the National Institutes of Health (NIH) Guidelines for the Care and Use of Laboratory Animals (8th edition).

\section{Cd concentration in renal tissue}

Kidney tissue specimens were simultaneously subjected to heavy and wet crushing for 2 hours with $1 \mathrm{M}$ nitric acid in the same time. The ashed specimens were diluted to $50 \mathrm{ml}$ with deionized water. The metal content was measured in $22.8 \mathrm{~nm}$ graphite furnaces using atomic absorption spectrophotometry (Perkin-Elmer 3100, Thermo Fisher Scientific, USA). The values of $\mathrm{Cd}$ were expressed as micrograms per gram of wet kidney tissue.

\section{Histology}

The specimens of kidney tissue were selected and fixed with $10 \%$ formaldehyde in PBS at room temperature for $24 \mathrm{~h}$. The specimens were embedded in paraffin, sliced at 4-5 $\mu \mathrm{m}$ thickness, and then dyed with haematoxylin and eosin (H\&E). The histological samples were evaluated by two investigators who were blinded to the applied power settings. Then, using light microscopy for analysis the histological characteristics and inflammatory status of glomerular and tubules.

\section{ELISA assay}

Elisa was performed using homogenates from tissue samples, which were collected from the cranial pole (whatever the part of the kidney you used) of the kidney, weighed, and immediately homogenized in $10 \mathrm{mM}$ phosphate buffer ( $\mathrm{pH} 7.4$ ) with ice-cold. Malondialdehyde (MDA), nitric oxide (NO), glutathione (GSH), catalase (CAT), superoxide dismutase (SOD), glutathione peroxidase (GPx) and glutathione reductase (GR) activities were measured according to manufacturer's Instructions by ELISA kits (Thermo Fisher Scientific, USA). A spectrophotometer was used to read the absorbance of each well at $450 \mathrm{~nm}$, and the contents of each well were calculated by using a standard curve.

\section{qRT-PCR}

Kidney tissue was dissected soon enough on ice and the total RNA was extracted by the Trizol reagent (Invitrogen, Carlsbad, CA). Then, the SuperScript RT kit from Invitrogen (Invitrogen, Carlsbad, CA) was used to reverse transcribed $2 \mu \mathrm{g}$ of total RNA from samples to CDNA. ABI PRISM7900 Sequence Detection System (Applied Biosystems, USA) with PowerUp ${ }^{\text {TM }}$ SYBR $^{\circledR}$ Green Master Mix (Thermo Fisher Scientific, USA) was used to perform Quantitative RT-PCR. Primer sequences were listed in Table 1. $2^{-\Delta \Delta C t}$ method was used for analysis of the relative expression levels of mRNA, and GAPDH served as internal control.

Table 1 - The sequences of mRNA primers.

\begin{tabular}{|c|c|c|}
\hline ID & Forward $\left(5^{\prime} \sim 3^{\prime}\right)$ & Reverse $\left(5^{\prime} \sim 3^{\prime}\right)$ \\
\hline $\mathrm{Bcl}-2$ & CTGGTGGACAACATCGCTCTG & GGTCTGCTGACCTCACTTGTG \\
\hline Bax & GGCGAATTGGCGATGAACTG & GGCGAATTGGCGATGAACTG \\
\hline TNF-a & ССТСТТСТСАТТССТGСТС & СТTСТССТССTTGTTGGG \\
\hline GAPDH & AAGGAAATGAATGGGCAGCC & TAGGAAAAGCATCACCCGGA \\
\hline
\end{tabular}

\section{Western blotting}

According to the manufacturer's instructions, the total protein in the cells or tissue was extracted using the RIPA buffer. 30ug of total proteins from each sample were separated by sodium dodecyl sulfate/polyacrylamide gel electrophoresis (SDS-PAGE) and then transferred to the polyvinylidene fluoride membrane through a wet transfer system. After blocking the membranes, they were incubated with the primary antibodies against $\mathrm{Bcl}-2, \mathrm{Bax}, \mathrm{TNF}-\alpha, \mathrm{Nrf2}$, Keap1, HO-1, GSH-Px, $\gamma$-GCS and NQO1 (all 1:800, Santa Cruz, USA). $\beta$-actin (1:5000, Sigma, USA) served as a loading control. Horseradish peroxidase (HRP)-labeled secondary antibody (1:1000, Sigma, USA) was used and incubated for $1 \mathrm{~h}$ at $25^{\circ} \mathrm{C}$. The band densities were quantified by the LICOR Odyssey infrared imaging system (LICOR Bio- science, Nebraska, USA).

\section{Statistical analyses}

GraphPad 8.0 was used to analyze data. All data were repeated as independent experiment three times and presented as mean \pm standard deviation (SD). ANOVA was used to analyze the significance of differentiation among experimental groups. ( $* \mathrm{P}<0.05,{ }^{*} \mathrm{P}<0.01$, $* * * P<0.001)$ Statistical significance was verified when $\mathrm{P}<0.05$. 


\section{- Results}

\section{PFE attenuated $\mathrm{CdCl}_{2}$ accumulation and damage in kidney tissues of rats pretreated with $\mathrm{CdCl}_{2}$}

Compared to control rats, $\mathrm{CdCl}_{2}$ injection in rats markedly increased the $\mathrm{Cd}$ concentration in renal tissue $(P<0.001)$, while the increased concentration of $\mathrm{CdCl}_{2}$ was markedly decreased by pretreatment of PFE to rats injected with $\mathrm{CdCl}_{2}(P<0.001)$ (Fig. 1A). Moreover, the kidney weight of rats exposed to $\mathrm{CdCl}_{2}$ alone was markedly higher than that of control rats $(P<0.001)$. However, pretreatment with PFE significantly reduced the increase in kidney weight, making it approximate to that of control group $(P<$ 0.01) (Fig. 1A). However, $\mathrm{CdCl}_{2}$ treatment decreased the body weight gain of rats $(P<0.001)$, while the preadministration of PFE increased the value compared to that of control rats $(P<0.05)$ (Fig. 1A). Compared with the control group, the oxidative stress in rats injected with $\mathrm{CdCl}_{2}$ showed a higher level of serum uric acid, urea and creatinine, revealing acute renal dysfunction, compared to that of control group (Fig. 1A). Pretreatment of PFE significantly reduced these metabolite increases $(P<0.001)$. In addition, the glomerular and renal tubules in the control group showed normal microstructure characteristics, while $\mathrm{CdCl}_{2}$ treated rats had vacuoles (black arrows), and was accompanied by severe inflammation and extensive degeneration (black star). PFE treatment rats had the normal microstructure of renal tubules, similar to histological in the control group. The renal tubules in the rats given PFE before $\mathrm{CdCl}_{2}$ showed normal histological structure. However, the vacuoles in some areas were still visible (Fig. 1B). Pretreatment of PFE to $\mathrm{CdCl}_{2}$ - injected rats significantly increased the histological characteristics in the renal tissue.

A
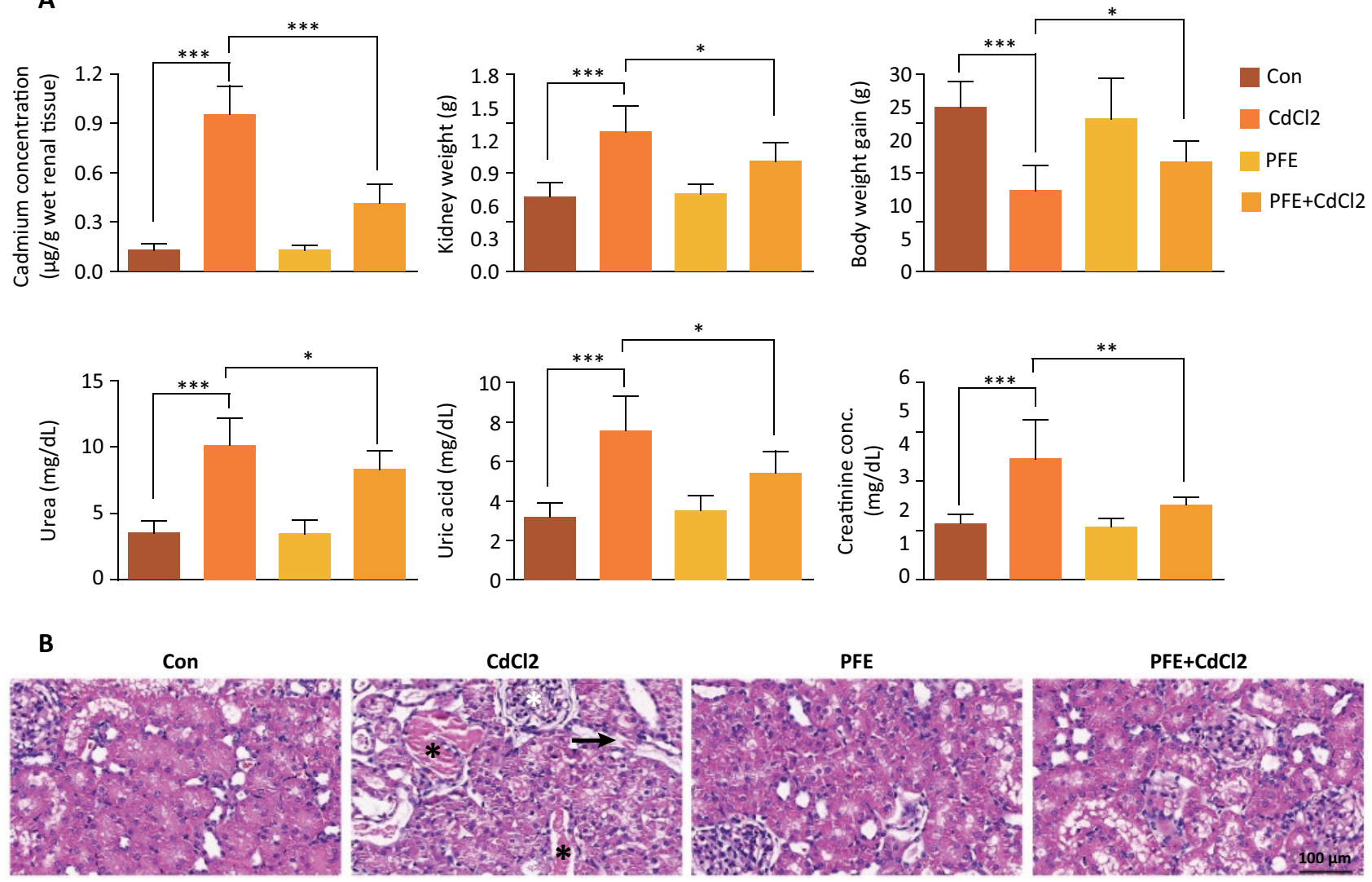

Figure 1 - The effects of PFE on kidney tissues of rats treated with $\mathrm{CdCl}_{2}$. (A) Effect of PFE on the accumulation of Cd in renal tissue, kidney weights, body weights, uric acid, urea, and creatinine plasma levels of rats treated with $\mathrm{CdCl}_{2}$, ${ }^{* * *} P<0.001$ vs. Con group, ${ }^{*} P<0.05,{ }^{* * *} P<0.001$ vs. $\mathrm{CdCl}_{2}$ group. (B) Histological characteristics of glomerular and tubules in control rats, $\mathrm{CdCl}_{2}$-treated rats, PFE-treated rats and the rats where PFE was administered before $\mathrm{CdCl}_{2}$, vacuoles (black arrows), inflammation and extensive degeneration (black star) (Scan bar, $\times 400$ ). 


\section{PFE pretreatment alleviated oxidative stress markers in $\mathrm{CdCl}_{2}$-injected rats}

$\mathrm{CdCl}_{2}$ treatment in rats markedly increased the yield of nitric oxide and MDA in the renal tissue $(P<0.001)$. Rats with oxidative stress induced by $\mathrm{CdCl}_{2}$ showed acute renal injury, which was proved by the significant decrease of GSH content in tissues $(P<0.001)$ (Fig. 2). $\mathrm{CdCl}_{2}$-injection in rats also markedly decreased the antioxidant enzymes, SOD, CAT, GPx and GR activities $(P<0.001)$. Pretreatment with PFE markedly decreased the yield of MDA $(P<0.001)$ and nitric oxide $(P<0.05)$ in the renal tissue and increased the level of GSH $(P<0.001)$, which were caused by $\mathrm{CdCl}_{2}$ injection. Furthermore, pretreatment of PFE increased the SOD $(P<0.05)$, GPx $(P<0.001)$, CAT $(P<0.01)$, and $\mathrm{GR}(P<0.001)$ activities compared with the enzyme activities in the $\mathrm{CdCl}_{2}$-treated group.
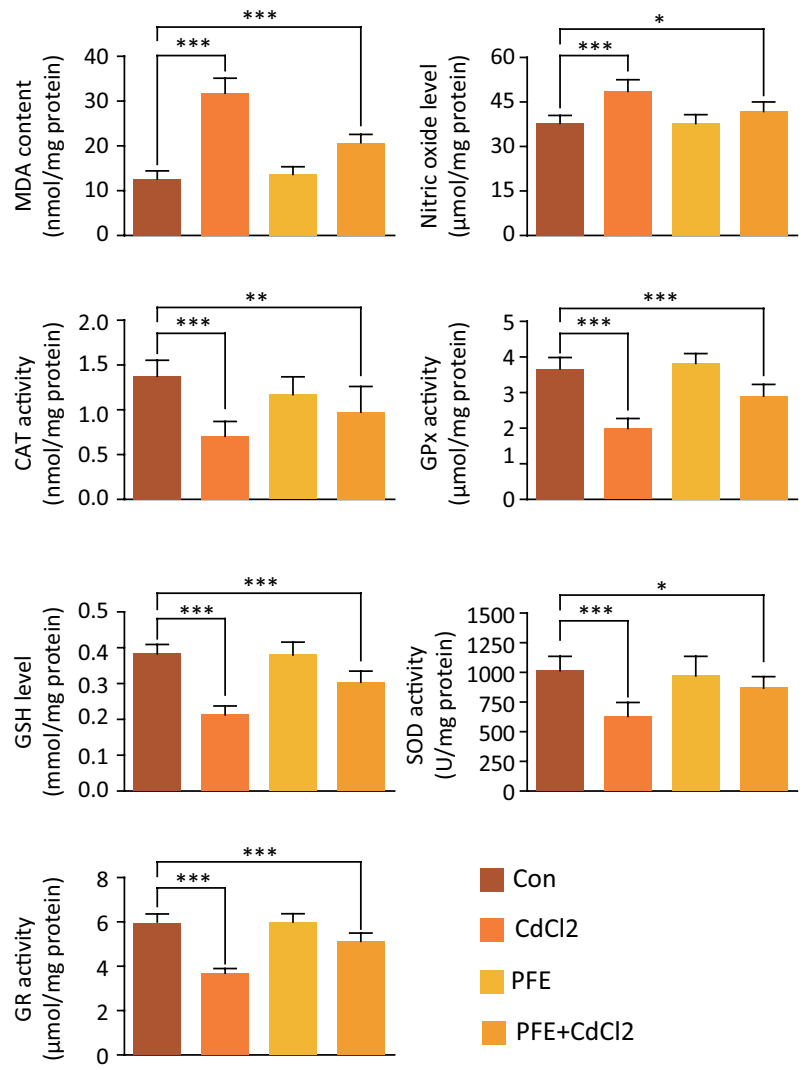

Figure 2 - Effects of PFE pretreatment on oxidative stress markers in rats treated with $\mathrm{CdCl}_{2}$. Analysis of MDA content, nitric oxide level, the SOD, CAT, GPx and $\mathrm{GR}$ activities in the renal tissue of control rats, $\mathrm{CdCl}_{2}$ treated rats, PFE-treated rats and the rats where PFE was administered before $\mathrm{CdCl}_{2}, * * * P<0.001$ vs. Con group, $* * P<0.01, * * * P<0.001$ vs. $\mathrm{CdCl}_{2}$ group.

\section{PFE pretreatment attenuated inflammatory and apoptosis in rats treated with $\mathrm{CdCl}_{2}$}

To detect whether the protective effects of PFE were due to its anti-inflammatory and anti-apoptotic characteristics, the Bcl-2, Bax, and TNF- $\alpha$ levels in the renal tissue were evaluated by qRT-PCR and western blot. Down-regulation of the Bcl-2 mRNA expression $(P<0.001)$ and up-regulation of Bax and TNF- $\alpha$ mRNA expression were observed in the $\mathrm{CdCl}_{2}$ treatment group $(P<0.001)$. However, these effects were significantly improved in the PFE pretreatment to $\mathrm{CdCl}_{2}$-injected rats $(P<0.001)$ (Fig. 3A). The results confirmed protective effects of PFE in the kidney of rats treated with $\mathrm{CdCl}_{2}$. In the rats treated with $\mathrm{CdCl}_{2}$, the Bax and TNF- $\alpha$ protein expression increased and the protein expression of $\mathrm{Bcl}-2$ was reduced $(P<0.001)$. PFE pretreatment to $\mathrm{CdCl}_{2}$-injected rats decreased the Bax and TNF- $\alpha$ protein expression, while increased $\mathrm{Bcl}-2$ expression in the renal tissue as compared to those expression in the $\mathrm{CdCl}_{2}$-injected rats (Fig. 3B).

A
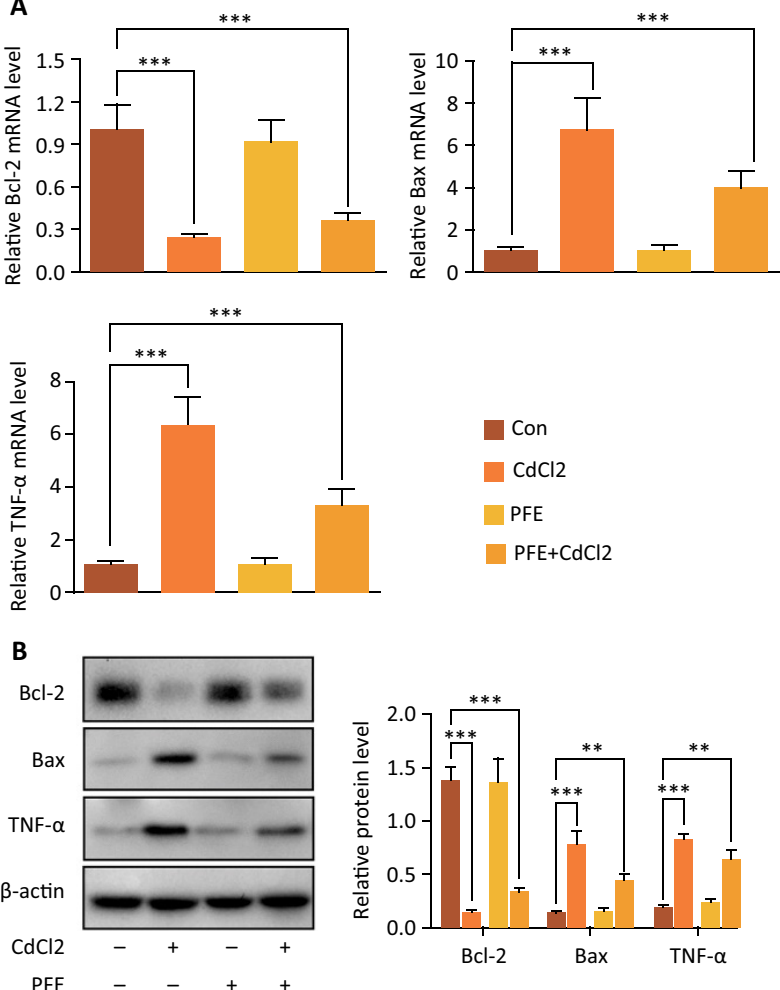

Figure 3 - The effects of PFE on the Bcl-2, Bax, and TNF- $\alpha$ genes expression in the renal tissue of rats treated with $\mathrm{CdCl}_{2}$. (A) The Bcl-2, Bax, and TNF- $\alpha$ mRNA expression was evaluated by $\mathrm{qRT}-\mathrm{PCR},{ }^{* * *} P<0.001$ vs. Con group, $* P<0.05$, $* * * P<0.001$ vs. $\mathrm{CdCl}_{2}$ group. (B) The $\mathrm{Bcl}-2$, Bax and TNF- $\alpha$ protein expression was evaluated by western blot, $* * * P<0.001$ vs. Con group, ${ }^{*} P<0.05, * * P<0.01$ vs. $\mathrm{CdCl}_{2}$ group. 


\section{PFE regulated Nrf2-Keap1 signaling pathway in rats treated with $\mathrm{CdCl}_{2}$}

The Nrf2, Keap1, HO-1, y-GCS, GSH-Px and NQO1 protein expression in the renal tissues of all groups was evaluated by western blot (Fig. 4). Compared with the control rats, the expression level of Keap 1 protein in $\mathrm{CdCl}_{2}$-injected group significantly increased $(P<0.001)$, while the expression level of Nrf2, HO-1, $p$-GCS, GSH-Px and NQO1 protein profoundly decreased. PFE pretreatment to $\mathrm{CdCl}_{2}$-injected rats markedly reduced the Keap-1 level $(P<0.05)$, while increased the Nrf2, HO-1, $y$-GCS, GSH-Px and NQO1 level $(P<0.05)$ in the renal tissue as compared to the $\mathrm{CdCl}_{2}$-injected rats.

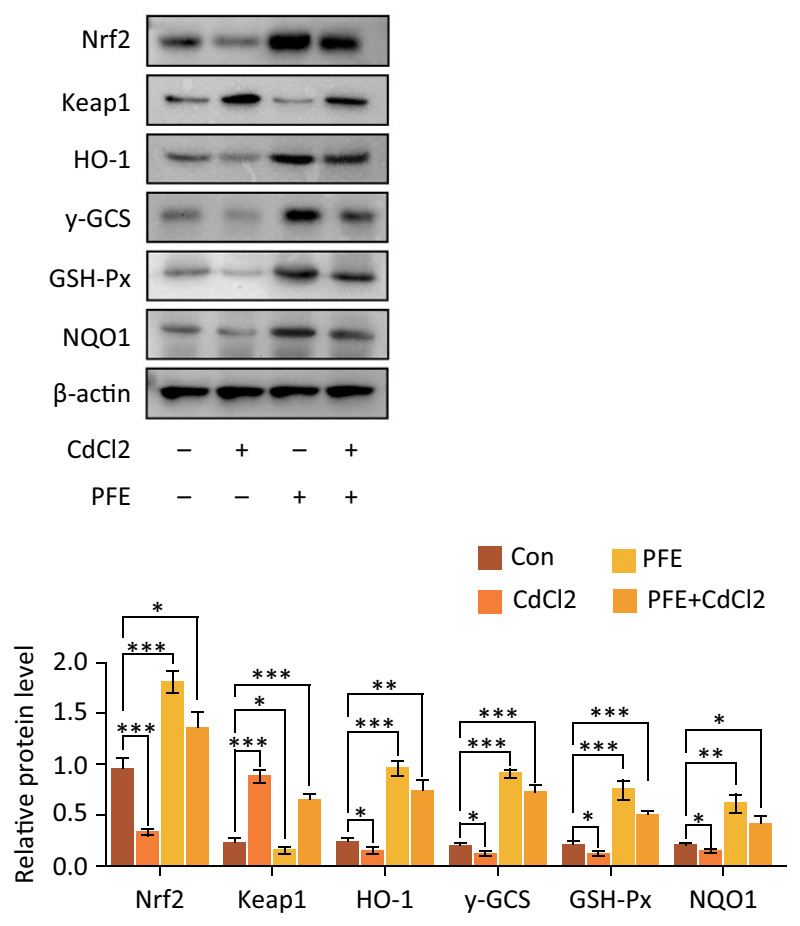

Figure 4 - The effects of PFE on Nrf2-Keap1 signaling pathway in rats treated with $\mathrm{CdCl}_{2}$. The protein expression of Nrf2, Keap1, HO-1, $y$-GCS, GSH-Px and NQO1 was evaluated by western blot, $* P<0.05, * * * P<0.001$ vs. Con group, ${ }^{* *} P<0.01,{ }^{* * *} P<0.001$ vs. $\mathrm{CdCl}_{2}$ group.

\section{- Discussion}

Pyracantha fortune fruit extract (PFE) is characterized as an excellent antioxidant ${ }^{11}$, rich in polyphenols such as rutin, hexose compound, and polymeric (epicate)catechin (proanthocyanidin 2, PB2) ${ }^{10}$. A growing number of evidences support the biological properties of PFE against antioxidants, anti-tumor and protection of liver damage ${ }^{11-13}$. Several studies in animal models showed that $\mathrm{Cd}$ accumulates mainly in kidney tissue ${ }^{19,20}$. Some studies showed that $\mathrm{Cd}$ therapy leads to kidney atrophy ${ }^{21}$, while other studies reported kidney hypertrophy after $\mathrm{Cd}$ therapy ${ }^{22}$. However, it is still unclear whether the damage caused by heavy metals can be alleviated by $P$. fortuneana. In this study, the effects of PFE on kidney injury in $\mathrm{CdCl}_{2}$-injected rats were investigated. The results showed that even if $\mathrm{CdCl}_{2}$ levels in the renal tissue were high, pretreatment with PFE in rats would significantly reduce the levels. Increasing kidney weights and the loss of body weight in $\mathrm{CdCl}_{2}$-injected rats observed in this investigation, was consistent with the results of previous reports ${ }^{5,23}$. PFE pretreatment in rats prevented these changes. We also examined markers that denote renal function and found that $\mathrm{CdCl}_{2}$ induced an increase in serum uric acid, urea and creatinine, and the results showed renal insufficiency. PFE pretreatment in rats decreased these indicators levels of renal dysfunction. Histological results confirmed the effect mentioned earlier, whether it was the destructive effects of $\mathrm{CdCl}_{2}$ and the protective effects of PFE ${ }^{24}$. PFE pretreatment in rats helped protect the kidneys from this damage, for example, by chelating $\mathrm{CdCl}_{2}$. Our results reinforced the hypothesis that PFE can attenuate $\mathrm{CdCl}_{2}$ accumulation and renal damage in kidney tissues of rats treated with $\mathrm{CdCl}_{2}$.

Malondialdehyde (MDA) is a prominent marker of oxidative stress, which reacts with proteins, DNA, and RNA in cells, leading to damage to kidney tissue ${ }^{25}$. Increased production of nitric oxide (NO) may activate NF-KB which increase the proinflammatory capacity of $\mathrm{CdCl}_{2}$, thus promoting the inducible NO synthase in macrophages ${ }^{26}$. Glutathione (GSH) exists both intracellularly and extracellularly in biological and allogeneic and reactive oxygen species (ROS) ${ }^{27}$. In recent years, several important catalytic enzymes that use GSH in defense mechanisms, such as glutathione S-transferase (GST) and glutathione reductase (GR), have shown different active patterns and injury treatments in leafy spurge tissue exposed to cold, drought and wounding treatments ${ }^{28}$. Superoxide dismutase (SOD) can catalyze the conversion of superoxide anions into $\mathrm{H}_{2} \mathrm{O}_{2}$ by a dismutation reaction ${ }^{29}$. Catalase (CAT) is an important antioxidant enzyme with heme as the active site prosthesis group ${ }^{30}$. In our current study, PFE, appears to reduce the $\mathrm{CdCl}_{2}$-induced renal toxicity by reducing the ability of MDA. Moreover, phenols have been reported to specifically remove $\mathrm{NO}^{31}$, which would clarify why PFE was so effective in reducing NO. The increase of GSH content in rat kidneys pretreated 
with PFE indicated that the PFE protects GSH from the decrease in the kidneys. The study found that the SOD activity of antioxidant enzymes in renal tissue of rats treated with $\mathrm{CdCl}_{2}$ significantly decreased. The $\mathrm{CdCl}_{2}-$ intoxicated rats significant inhibited the free radical capture enzyme sod and cat activity. Moreover, $\mathrm{CdCl}_{2}$ did not activate GPX and GR. The depletion of GSH content and increased MDA levels led to a decrease in GPX and $\mathrm{GR}$ activity during $\mathrm{CdCl}_{2}$ poisoning. PFE pretreatment prevented each protein from being altered, suggesting that PFE had a protective effect against oxidase, which may be due to the scavenging activity of free radical of the PFE.

Previous studies reported that initiation of the $\mathrm{Bax}$ and $\mathrm{BCl}-2$ are the most noteworthy way to relate to apoptotic signals activated in vitro ${ }^{32}$. TNF- $\alpha$ is a cytokine produced by activated macrophages to respond to pathogens and other harmful stimuli and is a necessary factor for local and systemic inflammation ${ }^{18}$. In addition, TNF- $\alpha$ amplifies and prolongs the inflammatory reactions through triggering other cells to release cytokines such as interleukin $-1 \beta$ and media such as NO and ROS, all of which promote further inflammation and tissue damage ${ }^{33}$. In the current study, both the mRNA and protein level of Bax and TNF- $\alpha$ increased in the kidney tissue, while mRNA and protein level of $\mathrm{BCl}-2$ reduced. PFE pretreatment in rats decreased the apoptosis in the kidney. In view of the ability of various plant chemicals to protect the apoptosis of nerve cells, the protective effect of PFE on renal tissue is related to inhibiting apoptosis. Furthermore, PFE pretreatment downregulated the TNF- $\alpha$ mRNA and protein expression compared to that of the $\mathrm{CdCl}_{2}$-injected rats' group, demonstrating the anti-inflammatory effects of PFE.

The SOD and GSH of antioxidation system can be regulated by the $\mathrm{Nrf2/Keap1} \mathrm{cascade} \mathrm{response} \mathrm{signaling}$ pathway ${ }^{34}$. The nuclear factor Nrf2 not only limits the activity of antioxidant, but also plays an important role in responding to various physiological and pathological stresses $^{35,36}$. The degradation of NRF2 is caused by Keap1/Cul3 ubiquitin-linked enzymes ${ }^{34}$. In the current study, the Keap-1 protein expression level was markedly increased, while the Nrf2, HO-1, p-GCS, GSH$\mathrm{Px}$ and NQO1 protein expression level was reduced in the $\mathrm{CdCl}_{2}$-injected group when compared with control rats. In addition, we found that the level of Nrf2, HO-1, Y-GCS, GSH-Px and NQO1 were elevated and the level of Keap 1 was decreased by pretreatment with PFE, which was consistent with the changes of SOD activity and GSH level. The protective effect of PFE on kidney tissue is associated with inhibition of inflammation, in light of the capacity of various phytochemicals to protect against stress-induced inflammation. Interestingly, PFE enhanced the kidney by suppressing the effects of $\mathrm{CdCl}_{2}$. Therefore, the expression levels of Nrf2, HO-1, y-GCS, GSH-Px and NQO-1 were increased in PFE $+\mathrm{CdCl}_{2}$ group. These data further confirmed that the protective effect of PFE therapy on oxidative stress may be through intervention in Nrf2/Keap 1 pathway.

\section{- Conclusions}

The pretreatment of PFE suggested protective roles against $\mathrm{CdCl}_{2}$-induced toxicity of kidney. The antioxidant and anti-apoptosis activity of PFE can achieve these antioxidant protection effects via the Nrf2/Keap 1 pathway. Therefore, the use of PFE may be beneficial for renal toxicity caused by $\mathrm{CdCl}_{2}$.

\section{- References}

1. Järup L, Åkesson A. Current status of cadmium as an environmental health problem. Toxicol Appl Pharmacol. 2009;238(3):201-8. doi: 10.1016/j.taap.2009.04.020.

2. Satarug $S$, Nishijo $M$, Ujjin $P$, Vanavanitkun $Y$, Moore $M R$. Cadmium-induced nephropathy in the development of high blood pressure. Toxicol Lett. 2005;157(1):57-68. doi: 10.1016/j.toxlet.2005.01.004.

3. Meyer KJ, Reif JS, Luben TJ, Mosley BS, Nuckols JR. Agricultural pesticide use and hypospadias in eastern Arkansas. Environ Health Perspect. 2006;114(10):1589-95. doi: 10.1289/ehp.9146.

4. Hong Y, Yan S. Cadmium transporters in the kidney and cadmium-induced nephrotoxicity. Int J Mol Sci. 2015;16(1):1484-94. doi: 10.3390/ijms16011484.

5. Ansari MA, Raish M, Ahmad A, Alkharfy KM, Ahmad SF, Attia SM, Ams A, Bakheet SA. Sinapic acid ameliorate cadmiuminduced nephrotoxicity: In vivo possible involvement of oxidative stress, apoptosis, and inflammation via NF-KB downregulation. Environ Toxicol Pharmacol. 2017;51:1007. doi: 10.1016/j.etap.2017.02.014.

6. Anju R, Anuj K, Ankita L, Manu P. Cellular mechanisms of cadmium-induced toxicity: a review. Int J Environ Health Res. 2014;24(4):378-99. doi: 10.1080/09603123.2013.835032.

7. Dorian C, Gattone VH, Klaasen CD. Renal cadmium deposition and injury as a result of accumulation of cadmium-metallothionein (CdMT) by the proximal convoluted tubules--A light microscopic autoradiography study with 109CdMT. Toxicol Appl Pharmacol. 1992;114(2):173-81. doi: 10.1016/0041-008X(92)90066-2.

8. El-Sharaky AS, Newairy AA, Badreldeen MM, Eweda SM, Sheweita SA. Protective role of selenium against renal toxicity induced by cadmium in rats. Toxicology. 2007;235(3):185-93. doi: 10.1016/j.tox.2007.03.014.

9. Gelder CWV, Flurkey WH, Wichers HJ. Sequence and structural features of plant and fungal tyrosinases. Phytochemistry. 1997;45(7):1309-23. doi: 10.1002/ chin.199741327. 
10. Zhao CF, Li S, Li SJ, Song GH, Yu LJ, Zhang H. Extraction optimization approach to improve accessibility of functional fraction based on combination of total polyphenol, chromatographic profiling and antioxidant activity evaluation: Pyracantha fortuneana fruit as an example. J Funct Foods. 2013;5(2):715-28. doi: 10.1016/j.jff.2013.01.017.

11. Chengfu $Y$, Changdong $W$, Youquan $B$, Tingxiu $X$, Xiuning H, Zhiwei W, Faping Y, Guosheng R, Geli L, Fangzhou S. Antioxidative and immunoprotective effects of Pyracantha fortuneana (Maxim.) Li polysaccharides in mice. Immunol Lett. 2010;133(1):14-8. doi: 10.1016/j.imlet.2010.04.004.

12. Chengfu $Y$, Zhihong $L$, Muhua $Y$, Xiaoxing W, Fan $P$, Fangxiang $X$, Tao C, Changdong W, Gohar M, Mohammad Amjad K. Effects of polysaccharides from selenium-enriched Pyracantha fortuneana on mice liver injury. Med Chem. 2015;11(8):7808. doi: 10.2174/1573406411666150602153357.

13. Sun $Q$, Dong $M$, Wang Z, Wang C, Sheng D, Li Z, Huang D, Yuan C. Selenium-enriched polysaccharides from Pyracantha fortuneana (Se-PFPs) inhibit the growth and invasive potential of ovarian cancer cells through inhibiting $\beta$-catenin signaling. Oncotarget. 2016;7(19):28369-83. doi: 10.18632/ oncotarget.8619.

14. Yuan C, Wang C, Bu Y, Xiang T, Huang X, Wang Z, Yi F, Ren G, Liu G, Song F. Antioxidative and immunoprotective effects of Pyracantha fortuneana (Maxim.) Li polysaccharides in mice. Immunol Lett. 2010;133(1):14-8. doi: 10.1016/j. imlet.2010.04.004.

15. Gao B, An D, Hybertson BM. The clinical potential of influencing Nrf2 signaling in degenerative and immunological disorders. Clin Pharmacol. 2014;6(default):19-34. doi: 10.2147/CPAA.S35078.

16. Li S, Song Z, Liu T, Liang J, Yuan J, Xu Z, Sun Z, Lai X, Xiong Q, Zhang D. Polysaccharide from Ostrea rivularis attenuates reproductive oxidative stress damage via activating Keap1Nrf2/ARE pathway. Carbohydr Polym. 2018;186:321-31. doi: 10.1016/j.carbpol.2018.01.075.

17. Dai Y, Zhou GH, Ye WC, Yao XS. Biphenyl glycosides from the fruit of Pyracantha fortuneana. J Nat Prod. 2006;69(7):1022-4. doi: 10.1021/np0600853.

18. Elkhadragy MF, Abdel MoneimAE. Protective effect ofFragaria ananassa methanolic extract on cadmium chloride ( $\mathrm{CdCl} 2)$ induced hepatotoxicity in rats. Toxicol Mech Methods. 2017;27(5):335-45. doi: 10.1080/15376516.2017.1285973.

19. Chen J, Du L, Li J, Song H. Epigallocatechin-3-gallate attenuates cadmium-induced chronic renal injury and fibrosis. Food Chem Toxicol. 2016;96:70-8. doi: 10.1016/j. fct.2016.07.030.

20. Haouem S, Hani AE. Effect of cadmium on lipid peroxidation and on some antioxidants in the liver, kidneys and testes of rats given diet containing cadmiumpolluted radish bulbs. J Toxicol Pathol. 2013;26(4):35964. doi: 10.1293/tox.2013-0025.

21. Hwang DF, Wang LC. Effect of taurine on toxicity of cadmium in rats. Toxicology. 2001;167(3):173-80. doi: 10.1016/S0300-483X(01)00472-3.

22. Pari L, Murugavel P. Role of diallyl tetrasulfide in ameliorating the cadmium induced biochemical changes in rats. Environ Toxicol Pharmacol. 2005;20(3):493-500. doi: 10.1016/j.etap.2005.05.009.
23. Dkhil MA, Al-Quraishy S, Diab MMS, Othman MS, Aref AM, Moneim AEA. The potential protective role of Physalis peruviana L. fruit in cadmium-induced hepatotoxicity and nephrotoxicity. Food Chem Toxicol. 2014;74:98-106. doi: 10.1016/j.fct.2014.09.013.

24. Kumar S, Pandey AK. Chemistry and biological activities of flavonoids: an overview. Scientific World J. 2013;2013:116. doi: 10.1155/2013/162750.

25. Kehrer JP, Lars-Oliver K. Free radicals and related reactive species as mediators of tissue injury and disease: implications for health. Crit Rev Toxicol. 2015;45(9):76598. doi: 10.3109/10408444.2015.1074159.

26. Reyes JL, Molina-Jijã N E, RodrãGuez-Muã $\mathrm{O} z$ R, BautistaGarcãA P, Debray-GarcãA Y, Namorado MC. Tight junction proteins and oxidative stress in heavy metals-induced nephrotoxicity. Biomed Res Int. 2013;2013(6):730789. doi: 10.1155/2013/730789.

27. Pastore A, Federici G, Bertini E, Piemonte F. Analysis of glutathione: implication in redox and detoxification. Clin Chim Acta. 2003;333(1):19-39. doi: 10.1016/S00098981(03)00200-6.

28. Davis DG, Swanson HR. Activity of stress-related enzymes in the perennial weed leafy spurge (Euphorbia esula L.). Environ Exp Bot. 2001;46(2):95-108. doi: 10.1016/S00988472(01)00081-8.

29. Bast A, Haenen GRMM. Interplay between lipoic acid and glutathione in the protection against microsomal lipid peroxidation. Biochim Biophys Acta. 1988;963(3):558-61. doi: 10.1016/0005-2760(88)90326-8.

30. Avital S, Almog A, Zvi M. Regulation and gene expression of heme synthesis under heavy metal exposure-review. J Environ Pathol Toxicol Oncol. 2010;29(2):137-58. doi: 10.1615/JEnvironPatholToxicolOncol.v29.i2.70.

31. Chirisa E, Boora F, Mukanganyama S. Evaluation of nitrite radical scavenging properties of selected Zimbabwean plant extracts and their phytoconstituents. Food Sci Tech. 2014;2014(2):1-7. doi: 10.1155/2014/918018.

32. Hanan $H$, Waleed AM. Betaine supplementation protects against renal injury induced by cadmium intoxication in rats: role of oxidative stress and caspase-3. Environ Toxicol Pharmacol. 2014;37(2):803-11. doi: 10.1016/j. etap.2014.02.013.

33. Alghasham A, Salem TA, Meki AR. Effect of cadmiumpolluted water on plasma levels of tumor necrosis factor-Ît, interleukin- 6 and oxidative status biomarkers in rats: protective effect of curcumin. Food Chem Toxicol. 2013;59(22):160-4. doi: 10.1016/j.fct.2013.05.059.

34. Ma Q. Role of nrf2 in oxidative stress and toxicity. Annu Rev Pharmacol Toxicol. 2013;53(1):401-26. doi: 10.1146/ annurev-pharmtox-011112-140320.

35. Pou Kuan L, Po Yee C, Na C, Hoiyan L, Kam Ming K. Schisandrin $B$ elicits a glutathione antioxidant response and protects against apoptosis via the redox-sensitive ERK/Nrf2 pathway in AML12 hepatocytes. Free Radic Res. 2011;45(4):483-95. doi: 10.3109/10715762.2010.550917.

36. Ying W, Li ZC, Liqing Y, Mai L, Mei T. Schisandrin B alleviates acute oxidative stress via modulating Nrf2/Keap1mediated antioxidant pathway. Appl Physiol Nutr Metab. 2018;44(1):1-6. doi: 10.1139/apnm-2018-0251. 


\section{Correspondence:}

Guojun Lian

School of Laboratory Medicine and Life Science, Wenzhou Medical University

Wenzhou China

Phone: 86-0577-86699125

Lianguojunawq@163.com

Received: Mar 19, 2019

Review: May 17, 2019

Accepted: June 15, 2019
Conflict of interest: none

Financial source: none

This is an Open Access article distributed under the terms of the Creative Commons Attribution License, which permits unrestricted use, distribution,

and reproduction in any medium, provided the original work is properly cited.

${ }^{1}$ Research performed at Department of Health Inspection and Quarantine, School of Laboratory Medicine and Life Science, Wenzhou city, Zhejiang province, China. 